\title{
Avaliando a presença espacial e autopresença em um jogo baseado em Realidade Virtual
}

\author{
Júlio Raphael de Oliveira Silva \\ Laboratório de Tecnologias para o Ensino Virtual e Estatística \\ Universidade Federal da Paraiba \\ João Pessoa, Brasil \\ jraphaeloliveira14@gmail.com
}

\author{
Liliane S. Machado \\ Departamento de Informática \\ Universidade Federal da Paraíba \\ João Pessoa, Brasil \\ liliane@di.ufpb.br
}

\begin{abstract}
Resumo- A sensação de presença está ligada intrinsecamente à realidade virtual e relaciona-se à capacidade de pertencimento do usuário ao ambiente. Esta sensação pode estar relacionada a diferentes aspectos como, por exemplo: a autopresença e presença espacial. Com isso, este trabalho tem como objetivo avaliar a presença espacial e autopresença em um jogo baseado em realidade virtual, desenvolvido para a conscientização da violência contra a mulher. O Caixa de Pandora é um serious games, que tem como objetivo conscientizar as pessoas sobre a violência contra a mulher. $O$ jogo passou por um processo de redesign que utilizou realidade virtual com ambientes $360^{\circ}$. Com o desenvolvimento da aplicação foram realizados testes a fim de medir os aspectos da presença espacial e autopresença, comparando com a versão anterior do Caixa de Pandora para dispositivos moveis. Os resultados destacaram que os aspectos da presença tiveram melhores resultados, quando comparados à sua versão mobile.
\end{abstract}

Palavras-chave - realidade virtual, autopresença, presença espacial, serious games, avaliação.

Abstract - The sensation of presence is intrinsically linked to virtual reality, bringing the user's ability to have feelings with that environment. This sensation can be found in different aspects such as: self-presence and spatial presence. This work aims to evaluate the spatial presence and self-presence in a game based on virtual reality, developed to raise awareness of violence against women. Caixa de Pandora is a serious game that aims to make people aware of violence against women. The game went through a redesign process that uses virtual reality with $360^{\circ}$ environments. With the development of the application, tests were performed in order to measure aspects of spatial presence and autopresence, comparing it to the previous version of Caixa de Pandora for mobile devices. The results highlighted that the presence aspects had better results, when compared to its mobile version.

Keywords - virtual reality, autopresence, space presence, serious games, evaluation.

\section{INTRODUÇ̃̃O}

A realidade virtual (RV) é uma tecnologia que permite aos seus usuários ter a capacidade de sentir, movimentar e interagir dentro de ambientes tridimensionais criados por computador [1]. A presença está diretamente ligada ao grau de envolvimento e imersão do usuário com o ambiente de $\mathrm{RV}[2]$.

A sensação de presença, pode ser definida como a capacidade de o usuário de estar e sentir o ambiente a sua volta. Com isso a presença pode ser considerada em diferentes aspectos, como físico, social, espacial e autopresença [3]. Cada um destes aspectos remete a um contexto específico da presença: como a manipulação de objetos, que está ligada a presença física; a comunicação entre usuários no ambiente virtual, que está relacionada à presença social; a presença espacial tem relação com a sensação do usuário de estar dentro do ambiente virtual, e a autopresença, que contempla o sentimento de que o usuário pertence àquele ambiente. A introdução da tecnologia RV em jogos ou simuladores, quando construída com a introdução de aspectos da presença, contribui com o aumento da sensação de satisfação dos usuários [3].

A realidade virtual pode enriquecer a experiência dos usuários de jogos. Como exemplo, podem ser citados jogos que foram desenvolvidos sem o uso desta tecnologia, mas que a adicionaram posteriormente para melhorar a experiência de seus jogadores, como o Star Trek: Bridge Crew (https://www.ubisoft.com/pt-br/game/star-trek/bridgecrew). Neste jogo, a utilização da RV permite aos seus jogadores realizarem missões junto aos seus tripulantes dentro do ambiente virtual, seja por interações com os tripulantes da nave ou com os painéis de controle presentes nela. Particularmente no caso dos serious games (SG), ou jogos com propósito, a sensação de presença poderia aproximar o jogador do conteúdo ou assunto do jogo.

A presença espacial visa prover aos seus usuários a sensação de sentir-se dentro do ambiente em realidade virtual e a autopresença relaciona-se à sensação de pertencimento do usuário. Considerando estes conceitos, foi realizado o redesign um serious games para utilizar RV com o intuito de trazer mais satisfação aos seus usuários, quando comparado à sua versão sem a abordagem da RV. Este trabalho tem como objetivo avaliar a presença espacial e autopresença neste serious games desenvolvido para a conscientização da violência contra a mulher.

\section{Metodologia}

A metodologia deste trabalho constituiu no desenvolvimento do questionário de avaliação de presença, no redesign de um serious games, na aplicação e análise de dados destes questionários.

\section{A. Questionário}

Para a avaliação da presença e autopresença neste projeto, foi desenvolvido um questionário que utiliza a escala de Likert de cinco pontos de respostas, onde estes pontos representam o grau de concordância do usuário com as afirmações (de "discordo totalmente" - 1, para "concordo totalmente" - 5). Para as perguntas foram feitas adaptações 
de questionários conhecidos e validados que abordam a presença: os questionários de Witmer e Singer [4], de Rigby e Ryan[5] e por fim o questionário de Baños et al. [6].

Witmer e Singer [4] desenvolveram um questionário que mede o grau em que os usuários sentem a presença em um ambiente virtual, utilizando o olhar de quatro fatores, que são: controle (capacidade de interação do usuário com o ambiente), sensorial (estímulos que os usuários possam sentir através dos seus sentidos), distração (isolamento do usuário do mundo real) e realismo (capacidade de que o ambiente virtual convence o usuário). Este questionário utiliza da escala de Likert de 7 pontos para as suas respostas e a medida é feita após o somatório dos pontos atribuídos de cada pergunta. Com isso os autores chegaram a uma correlação entre os itens com a pontuação total do questionário, com seus resultados, influenciados os fatores de presença no usuário. Com isso foram selecionadas e adaptadas algumas perguntas deste questionário, já que este questionário é voltado para avaliar aplicações de realidade virtual.

Rigby e Ryan [5] desenvolveram um modelo, conhecido como PENS, que tem como intuito medir a experiência do jogador para verificar quão satisfatórias estas são ao jogador. Este modelo é voltado para o universo dos jogos digitais e considera os seus elementos de necessidades psicológicas básicas de um ser humano, além da sensação de presença e de controles intuitivos.

Baños et al. [6] elaboraram o "The Reality Judgement and Presence Questionnaire" que avalia a presença e o julgamento do jogador sobre a realidade. Os itens presentes neste questionário foram baseados em outros questionários e suas respostas utilizam a escala de Likert variando de zero (de modo algum) a 10 (absolutamente). Por fim, este questionário possui o número total de 77 itens que cobrem os seguintes aspectos: 14 itens relacionados ao conceito de julgamento da realidade; 17 itens relacionando o conceito de presença; 14 itens relacionam o envolvimento emocional; 6 itens relacionam a interação; 4 itens falam sobre o controle; 4 itens relacionam a atenção; 7 itens estão relacionados sobre o realismo; 3 itens relaciona sobre o percentual de congruência e contínuo; 8 itens falam sobre a expectativa e possibilidades de antecipação.

A utilização de elementos destes três questionários, de maneira combinada, visou avaliar a presença dos usuários de uma forma ampliada àquela proposta por Witmer e Singer [4], que considerava apenas ambientes de RV. Assim, os aspectos de presença encontrados nos outros 2 questionários foram também considerados.

\section{B. Serious Games em RV}

O jogo desenvolvido foi um redesign do SG Caixa de Pandora. O SG Caixa de Pandora tem como intuito a conscientização sobre a violência contra a mulher, explorando as habilidades cognitivas de seus jogadores por desafios espalhados ao longo do jogo [7]. O jogo possui uma abordagem 2D no qual uma sequência de imagens desenhadas (tarefa) é apresentada seguida por uma pergunta. Originalmente desenvolvido para execução em computadores pessoais, este serious game já havia passado por um processo de redesign para a readequação de diálogos e adaptação para dispositivos móveis a fim de alcançar um público-alvo maior e ser executado em dispositivos com sistema Android [8]. Esta versão foi chamada Caixa de Pandora mobile.
A partir dos desafios originais presentes no Caixa de Pandora, desde sua primeira versão, foi realizado um novo processo de redesign deste jogo, transformado a sequência de imagens (tarefas) em conteúdos a serem explorados em cenas em $360^{\circ}$. Deste modo, em vez de visualizar uma sequência de imagens 2D (Figura 1a), agora o jogador dirige seu olhar livremente para pontos específicos do cenário $360^{\circ}$ para acessar as tarefas (Figura 1b). Foi mantida a plataforma Android para a exportação da aplicação, sendo que agora é necessário o uso de um head up display para jogar, no qual o usuário encaixa o aparelho de telefone para visualizar o cenário (Figura 2).

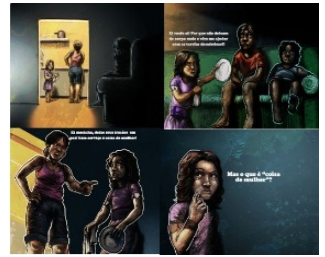

(a)

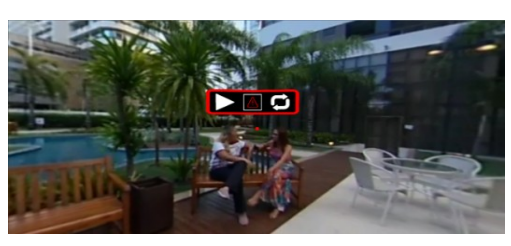

(b)
Figura 1: (a) Cenas dos jogos Caixa de Pandora mobile e (b) Caixa de Pandora $360^{\circ}$

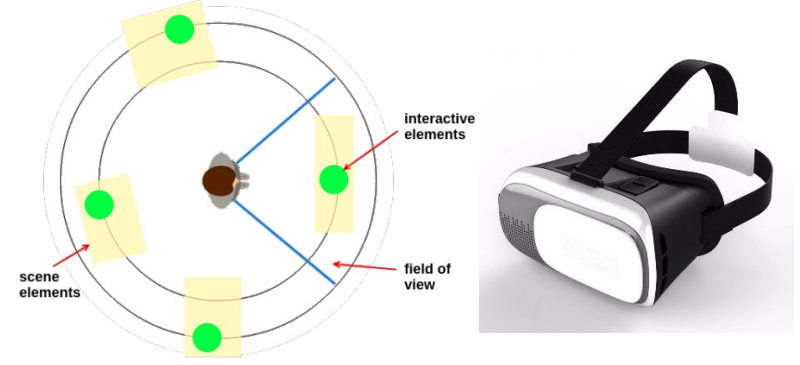

Figura 2: (a) cenário $360^{\circ} \mathrm{e}$ (b) head up display.

É importante mencionar que este jogo depende de aparelhos que contenham giroscópio e acelerômetro, capazes de detectar os movimentos espaciais. Deste modo, o jogo em $360^{\circ}$ permite aos seus usuários estarem dentro do ambiente como um espectador para observar um vídeo ou imagem relacionada a cada tarefa.

Para a construção da aplicação foi utilizado o ambiente de desenvolvimento Unity $3 D$, que utiliza a linguagem C\# para a construção de seus scripts e junto a esse ambiente foi utilizado a API do Google Cardboard.

\section{Aplicação dos Questionários}

A pesquisa com os usuários foi realizada a partir de um recorte feito no SG Caixa de Pandora mobile para que ele tivesse só os desafios que estavam presentes no redesign do jogo em RV $360^{\circ}$. Sendo assim as pessoas testaram ambos os jogos, mobile e em RV, em ordem aleatória, e respondiam o questionário de presença após cada jogada.

Os testes e aplicação dos questionários foram realizados no ano de 2019 na EXPOTEC, uma feira de tecnologia que ocorre anualmente em na cidade de João Pessoa/PB, junto ao público que estava visitando a feira. Para isso, era explicado às pessoas do que se tratava o teste $\mathrm{e}$ como ele ocorreria.

\section{Desenvolvimento}

Esta seção apresentará o questionário desenvolvido, o processo de desenvolvimento da aplicação e a aplicação do questionário. 


\section{A. Questionário}

A construção do questionário utilizado para a avaliação neste trabalho se deu com a junção de 22 perguntas encontradas nos questionários propostos por Witmer e Singer [4] e Rigby e Ryan [5] e, por fim, o questionário proposto por Baños et al. [6], fazendo adaptações de perguntas encontradas neles. $\mathrm{O}$ quadro 1 apresenta quais perguntas foram selecionadas e adaptadas de cada um dos questionários.

Quadro 1: Questões selecionadas dos questionários sobre Presença.

1 Ao jogar, sinto-me transportado para outro tempo e lugar; $\left(^{*}\right)$

2 Ao jogar o jogo, sinto-me como se fizesse parte da história (ou contexto apresentado no ambiente); $(*)(* *)$

3 Eu tive reações a eventos e personagens do jogo como se fossem personagens reais; $(*)$

4 Me senti impactado pelo contexto apresentado pelo ambiente virtual do jogo; $(* * *)$

5 O ambiente virtual foi capaz de induzir emoções em mim (respostas emocionais); (***)

$6 \mathrm{Me}$ senti emocionalmente envolvido na experiência proporcionada pelo ambiente virtual do jogo; $(* * *)$

7 A experiência proporcionada, no geral, pareceu realista; $(* * *)$

8 Me senti um participante ativo dentro do ambiente do jogo; $(* * *)$

9 Senti que os aspectos visuais do ambiente/jogo (imagens, cenas etc.) me envolveram no assunto do jogo; $(*)$

10 Senti que os aspectos sonoros do ambiente/jogo (músicas, efeitos sonoros etc.) me envolveram no assunto do jogo; (*)

11 Senti que os aspectos visuais do ambiente/jogo me distraíam enquanto jogava; $(*)$

12 Senti que mesmo no ambiente virtual, eu estava consciente dos eventos ocorridos no mundo real, não me senti transportado para o ambiente; $(*)$

13 Eu fui capaz de examinar o ambiente virtual através da visão; (*)

14 O ambiente virtual foi responsivo às ações que eu iniciei; $(*)$

15 Eu fui capaz de examinar objetos mais de perto; $(*)$

16 Eu fui capaz de examinar objetos por múltiplos pontos de vista; $(*)$

17 Me senti proficiente em mover e interagir com o ambiente virtual ao final da experiência; $(*)$

18 Os objetos se movendo pelo ambiente virtual tornou-o mais convincente; $(*)$

19 A experiência dentro do ambiente virtual pareceu consistente com a experiência no mundo real; $(*)(* * *)$

20 Me senti envolvido com o ambiente virtual a ponto de me "esquecer" do mundo real; $(*)(* * *)$

21 Me senti fisicamente presente no ambiente virtual; $(* * *)$

$22 \mathrm{O}$ que vi/experienciei no ambiente virtual foi similar a realidade; $(* * *)$

23 Me senti imerso no ambiente virtual; $(* * *)$

24 Me senti um passivo espectador dentro do mundo virtual; $(* * *)$

25 Experimentei atrasos entre minhas ações e os efeitos delas no ambiente do jogo; $(* * *)$

\begin{tabular}{|ll|}
\hline 1 & $(*)[4]$ \\
2 & $(* *)[5]$ \\
3 & $(* * *)[6]$ \\
\hline
\end{tabular}

O Questionário desenvolvido contém 22 questões, sendo que 16 abordam o aspecto da presença espacial e 6 abordam a autopresença. Observa-se que o número de questões deste questionário, diminuiu em relação ao Quadro I, pelo fato de algumas tratarem do mesmo aspecto da presença. Os quadros 2 e 3 mostram as questões do questionário final quanto à presença espacial e à autopresença, respectivamente.
Quadro 2: Questões sobre Presença Espacial do questionário final.

P1 - Me senti imerso no ambiente virtual

P2 - O conteúdo apresentado pelo ambiente virtual ajudou a envolver-me no jogo.

P3 - Senti que os aspectos visuais (imagens, cenas etc.) do jogo me envolveram na temática do jogo.

P4 - Senti que os aspectos sonoros (músicas, efeitos sonoros etc.) presentes me envolveram na temática do jogo.

P5 - A experiência dentro do ambiente do jogo pareceu consistente com a experiência no mundo real.

P6 - O ambiente virtual respondeu as minhas interações e ações de forma satisfatória.

P7 - Me senti capaz de interagir com o ambiente virtual ao final da experiência.

P8 - Me senti envolvido com o ambiente virtual de forma que consegui me distrair do mundo real.

P9 - Ao jogar, sinto-me transportado para outro tempo e lugar.

P10 - Me senti envolvido emocionalmente pelo ambiente virtual.

P11 - Senti que as minhas ações modificam o ambiente do jogo.

P12 - Eu não tinha conhecimento do que acontecia ao meu redor enquanto navegava pelo ambiente virtual.

P13 - Experimentei atrasos entre minhas ações e os efeitos delas no ambiente do jogo.

P14 - Senti que os aspectos visuais/sonoros do jogo me distraíam enquanto jogava.

P15 - Senti que mesmo no ambiente virtual, eu estava ciente do mundo real ao meu redor enquanto navegava no mundo virtual.

P16 - O cenário do jogo me pareceu realista.

Quadro 3: Questões sobre Auto Presença do questionário final.

P17 - Ao jogar o jogo, sinto-me como se fizesse parte da estória (ou contexto apresentado no ambiente).

P18 - Eu tive reações a eventos e personagens do jogo como se fossem personagens reais.

P19 - Me senti impactado pelo contexto apresentado pelo ambiente virtual do jogo.

P20 - O ambiente virtual foi capaz de induzir respostas emocionais em mim.

P21 - Me senti emocionalmente envolvido na experiência proporcionada pelo ambiente do jogo.

P22 - Fui capaz de me identificar ou ter sentimentos de empatia com o personagem virtual no ambiente do jogo.

\section{B. Desenvolvimento da Aplicação}

Para a construção da aplicação em RV $360^{\circ}$ utilizada neste trabalho foi implementado no jogo um sistema de interação natural por meio da movimentação da cabeça, além da modelagem de cenários, de moda a trazer elementos interativos aos usuários. Também foi desenvolvido um sistema de controle de áudio em 3D, com a intenção de trazer mais imersão do usuário na aplicação.

A nova forma para a interação dos usuários utilizou o conceito de gaze, ou direção do olhar. Esta forma utiliza só a visão do usuário para a sua interação, já que o jogador só precisa fixar a observação no marcador no ambiente virtual por alguns instantes para que a interação com o marcador ocorra. Esta forma de interação é mais barata e natural quando comparada à que utiliza o joystick, já que não precisa de nenhum outro dispositivo conectado para o seu funcionamento. A Figura 3 mostra o funcionamento da gaze.

Os ambientes em RV foram criados com um misto de ambientes virtuais com gravações reais. Sendo assim, os desafios foram gravados com pessoas e ambientes reais. Portanto, os desafios foram distribuídos em áreas da cena $360^{\circ}$ e com isso em vez de ser gravado um desafio por cena, foi possível gravar alguns desafios por cena, tendo que cada desafio ocupava uma área determinada no cenário $360^{\circ}$, como mostra a Fig. 4. 

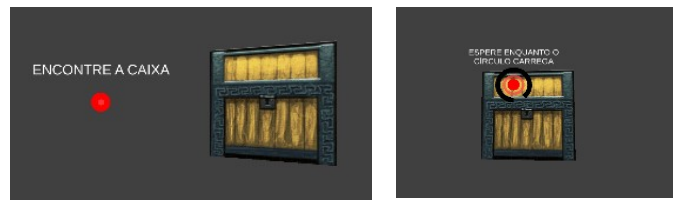

Figura 3: A utilização da gaze no SG.

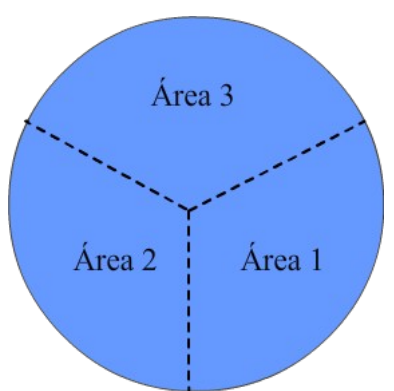

Figura 4: Distribuição dos desafios na cena.

Por fim, foi desenvolvido um roteiro para que os desafios escolhidos correspondem àqueles da versão mobile quanto ao conceito e propósito apresentados. O enredo para a versão RV $360^{\circ}$ uniu desafios em um mesmo cenário que ocorriam simultaneamente. A Figura 5 mostra o cenário escolhido para a ocorrência de 3 desafios, separados conforme mostrado na Fig. 4.

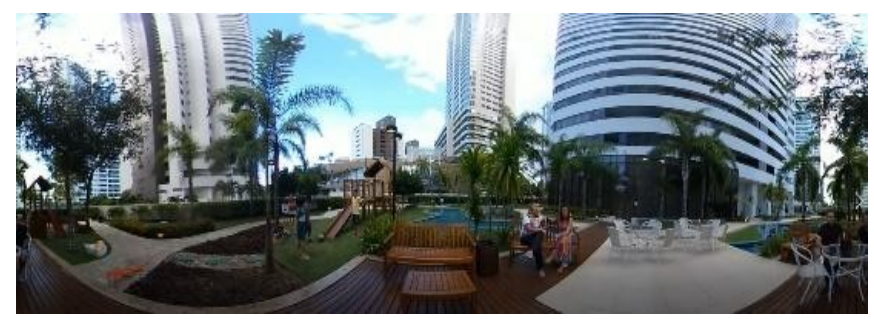

Figura 5: Foto panorâmica do cenário escolhido.

Os áudios de cada desafio foram gravados separadamente e o jogo teve implementado um sistema que usa a rotação da cabeça do jogador na cena no eixo y, variando o volume do áudio de acordo com a área que este jogador observa. Assim, o volume do áudio varia de acordo com as áreas apresentadas na figura 3. A Figura 6 mostra como este processo ocorre: na imagem A, o jogador está observando a área 1, porém, quando ele gira a cabeça e passa a olhar a área 2, o áudio presente na cena aumenta na área 2 e diminui nas demais. Para tanto, os áudios de cada área foram gravados separadamente.

\section{Aplicação dos Questionários}

A aplicação dos questionários contou com 42 participantes, que jogaram em ordem aleatória a versão mobile e RV $360^{\circ}$, respondendo após cada jogada o mesmo questionário.

Desta amostra podemos destacar que $71,4 \%$ dos participantes eram do público masculino, predominância da faixa etária entre 15 a 20 anos (42,84\%). Quanto à formação acadêmica, o ensino superior foi selecionado por $64,3 \%$ dos participantes, enquanto o ensino médio foi selecionado por $35,7 \%$ destes. Quanto à utilização de jogos, foi informado pelos participantes que: $13(31,0 \%)$ jogavam semanalmente, $12(28,6 \%)$ jogavam raramente e $17(40,5 \%)$ jogavam diariamente. Nenhum participante informou não ser usuário de jogos.

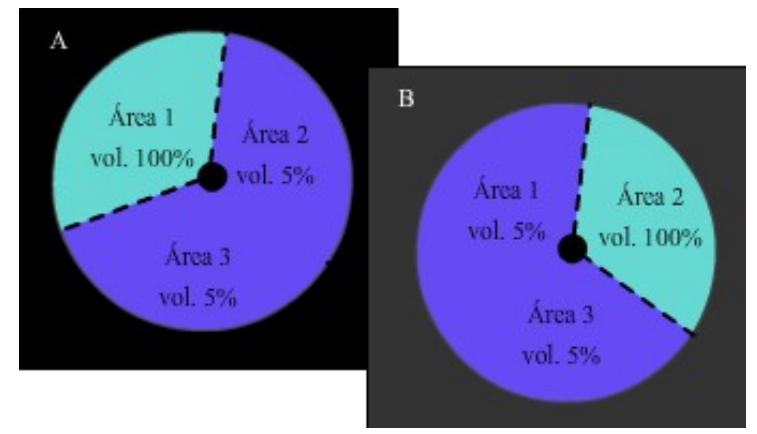

Figura 6: Áreas de observação da cena: a área em verde destaca a direção de observação do jogador

Quanto à presença espacial, os valores obtidos pelas questões P1, P2, P3, P5, P7, P8, P9, P12 e P16 receberam no valor 5 da escala uma taxa maior que $50 \%$. Se comparado ao jogo na versão mobile, pode-se perceber que houve ganho na presença espacial. Particularmente, nas questões P13, P14 e P15 esperava-se que as pessoas marcassem os pontos de 1 a 3 da escala, o que ocorreu, mas não no grau esperado. Entendemos que este fato ocorreu pelo elevado barulho do ambiente dos testes, durante a feira de tecnologia. Nas demais perguntas não foi possível obter diferença significativa. Se comparados aos resultados obtidos na versão mobile, podemos destacar que a tecnologia RV permitiu ao jogo ampliar aos seus jogadores a sensação de estar dentro daquele ambiente, diferentemente da sua contraparte mobile que apresentou maior frequência de resposta nos pontos 2 e 3 .

O questionário sobre autopresença obteve em sua avaliação, obteve resultados que variaram entre indeciso e concordo totalmente. Mesmo assim podemos citar que estes resultados são positivos, pois, os resultados na escala 4 e 5 foram sempre superiores a $50 \%$ das respostas. Podemos destacar a questão P22 que obteve uma porcentagem de 50\% das respostas na escala 5, demonstrando que os jogadores sentiram empatia com os personagens. Se comparados aos resultados obtidos na versão mobile, observou-se que em ambos os casos os jogadores tiveram sentimentos de pertencimento ao jogo, com uma leve melhora da versão $360^{\circ}$ quando comparada à versão mobile. Entretanto, devido ao tamanho da amostra, essa variação não pode ser considerada significativa. Os resultados obtidos pela avaliação da presença espacial e autopresença, podem ser vistos no gráfico 1 .

\section{CONCLUSÃO}

Este trabalho teve como objetivo realizar a avaliação da presença espacial e autopresença em um serious games baseado em realidade virtual $360^{\circ}$. Para tanto, uma nova versão, baseada no propósito e conceitos de uma versão anterior, foi desenvolvida.

O SG desenvolvido permitiu verificar o impacto da presença em uma nova abordagem com a utilização de realidade virtual em $360^{\circ}$. Com esta nova abordagem, um novo enredo foi construído para abrigar os desafios no cenário $360^{\circ}$, além da inclusão de elementos que não estavam presentes nas versões anteriores, de modo a contemplar aspectos da presença espacial e da autopresença. 
Com os resultados dos testes foi observado que o SG desenvolvido com $\mathrm{Rv} 360^{\circ}$ proporcionou aos jogadores maior sensação de presença quando comparado a versão mobile. Entretanto, a amostra utilizada nesta pesquisa contou apenas com 42 participantes, não permitindo obter validade estatística nos resultados. Estudos futuros pretendem ampliar essa amostra.

\section{AgRADECIMENTOS}

Os autores agradecem pelo apoio financeiro à Universidade Federal da Paraíba com bolsa PIBIC, e ao CNPq, processo 315298/2018-9.

\section{REFERÊNCIAS}

[1] Kirner, C.; Siscoutto, R. (2007) Realidade Virtual e Aumentada Conceitos, Projeto e Aplicações. In: Symposium on Virtual and Augmented Reality, 9., , Petrópolis. p. 7 - 10.

[2] RIVA, Giuseppe et al. (2007) Affective interactions using virtual reality: the link between presence and emotions. CyberPsychology \& Behavior, v. 10, n. 1, p. 45-56.

[3] S.-A. A. Jin. (2011) "I feel present. Therefore, I experience flow:" a structural equation modeling approach to flow and presence in video games", Journal of Broadcasting \& Electronic Media, vol. 55, no. 1, pp. 114-136.

[4] Witmer, B.G.; Singer, M.J. (1998) Measuring presence in virtual environments: A presence questionnaire. Presence 7(3): 225-240.

[5] S. Rigby and R. Ryan, (2007) The player experience of need satisfaction (PENS) model. Immersive Inc, p. 1-22.

[6] R.M. Baños, C. Botella, A. Garcia-Palacios, H. Villa, C. Perpiña, and M. Alcañiz, (2000) Presence and reality judgment in virtual environments: A unitary construct?. CyberPsychology \& Behavior. 3(3), 327-335.

[7] Almeida, L.R.; et al. (2018) The Caixa de Pandora game: changing behaviors and attitudes towards violence against women. Computers in Entertainment 16(3).

[8] Oliveira, J.R.; Félix, Z. Almeida, L.; Medeiros, A.; Machado, L.S. (2019) Redesign do Serious Game Caixa de Pandora para Dispositivos Móveis. Comunicações em Informática 2(2): 9. DOI: $10.22478 /$ ufpb.2595-0622.2018v2n2.40725
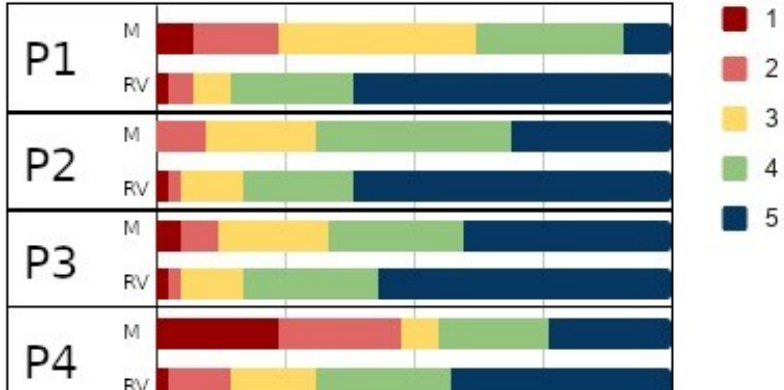
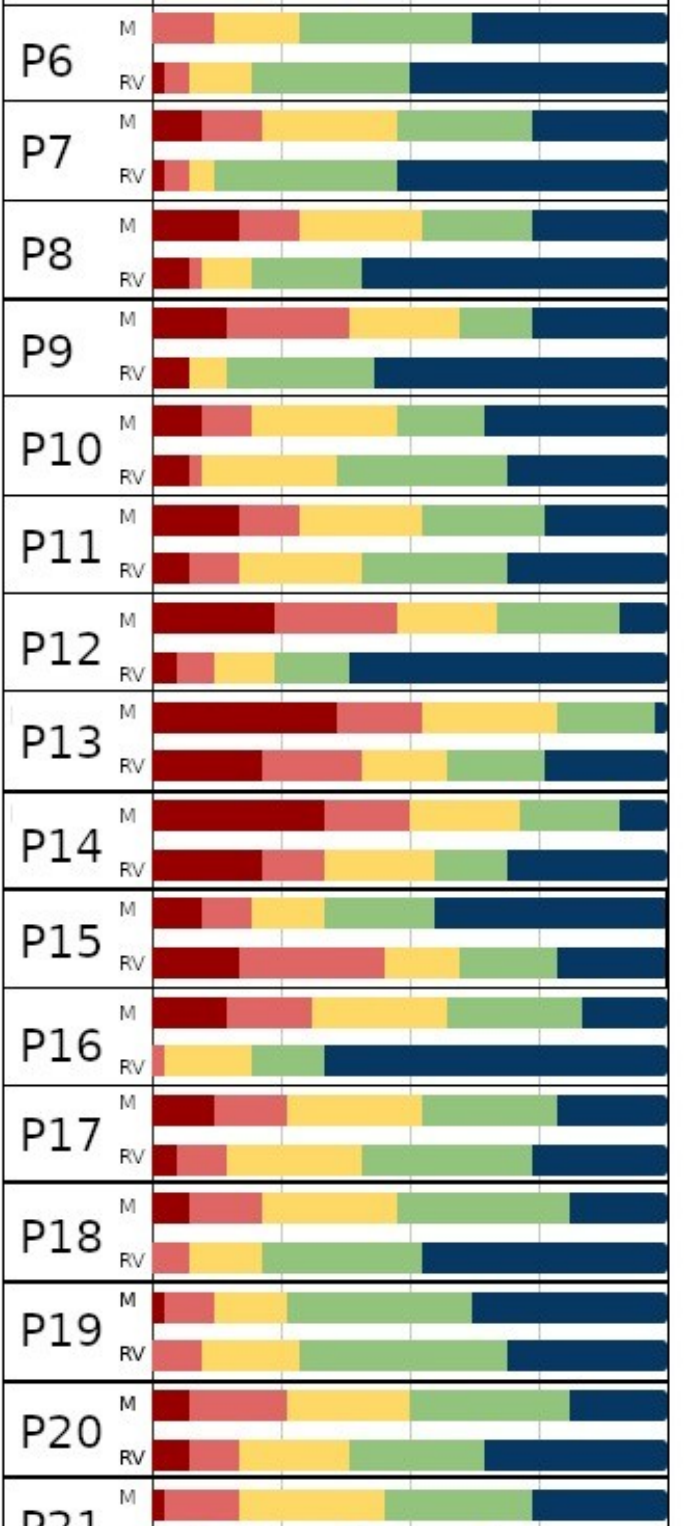

P21

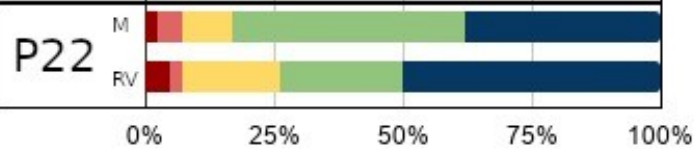

$\mathrm{M}$ - versão mobile

RV - versão RV $360^{\circ}$

Cores na escala de Likert

Gráfico 1: Resultado das Avaliações, considerando as duas versões testadas e respostas na escala de Likert. 